\title{
FAMÍLIAS HOMOAFETIVAS E PLURALIDADE: UMA ANÁLISE SOBRE O RECONHECIMENTO DE DIREITOS LGBTI NOS TRIBUNAIS SUPERIORES BRASILEIROS
}

\author{
Ramon Silva Costa* \\ Samuel Rodrigues de Oliveira**
}

Resumo: $\mathrm{O}$ artigo trata sobre o reconhecimento de direitos para famílias homoafetivas nos tribunais superiores brasileiros e objetiva investigar como ocorre o acesso a esses direitos e o debate sobre eles, considerando-se a pluralidade social brasileira, a majoritária participação da advocacia privada nesses processos, o papel da Defensoria Pública e a interseccionalidade de opressões que agem sobre essas populações. A metodologia empregada é a análise de decisões, publicadas entre 2011 e 2018 e coletadas nos sites dos tribunais, somada a revisão bibliográfica. Sendo assim, são propostos mecanismos iniciais para um reconhecimento complexo dos direitos de famílias LGBTI no Brasil.

Palavras-chave: Reconhecimento, Pluralidade, Tribunais Superiores, Família Homoafetiva, LGBTI.

\section{LGBTI FAMILIES AND PLURALITY: AN ANALYSIS OF THE RECOGNITION OF LGBTI RIGHTS IN THE BRAZILIAN SUPERIOR COURTS}

Abstract: The article analyzes the recognition of rights for LGBTI families in Brazilian Higher Courts and aims to investigate how the access to and debate on these rights occur, taking into account the Brazilian social plurality, the majority participation of private advocacy in these processes, the role of Public Defender offices and the intersectionality of oppressions that act upon these populations. The methodology used is the analysis of decisions published between 2011 and 2018 and collected on the courts' websites, along with bibliographic review. Thus, we propose initial mechanisms for a complex recognition of the rights of LGBTI families in Brazil.

Keywords: Recognition, Plurality, High Courts, LGBTI Family, LGBTI.

\footnotetext{
* Graduado em Direito pela Universidade Federal Fluminense (UFF) e mestrando bolsista CAPES em Direito e Inovação pela Universidade Federal de Juiz de Fora (UFJF). E-mail: ramoncostta@ outlook.com.

** Graduado em Direito e mestrando em Direito e Inovação pela Universidade Federal de Juiz de Fora (UFJF). Email: samuelrdeoliveira@gmail.com.
} 


\section{INTRODUÇÃO}

O Estado democrático de Direito e a efetivação dos direitos humanos enfrentam os desafios da realidade por meio da doutrina e da jurisprudência que são constantemente perpassadas pelos conflitos e sociabilidades gerados pela crescente complexidade da vida contemporânea. Nesse campo, podem ser citadas a diversidade sexual e as múltiplas configurações familiares, como as uniões entre pessoas do mesmo sexo, que configuram uma realidade expressiva no Brasil, mas que enfrentam obstáculos para um reconhecimento efetivo e plural (DIAS, 2000).

No processo de reconhecimento de direitos para as famílias homoafetivas ocorreram decisões judiciais de destaque, como o julgamento conjunto da ADI 4.277 e ADPF 132 pelo Supremo Tribunal Federal que conferiu o direito à união estável para casais homossexuais por meio da aplicação analógica do art. 1.723 do Código Civil. Contudo, tal fato não encerrou a demanda por reconhecimento destes sujeitos e restou em novos desafios para a efetivação de direitos deste grupo. Assim, tais direitos ainda geram um relevante debate sociopolítico (CARDINALI, 2018).

Nesse sentido, a questão posta em evidência é: como o reconhecimento de direitos pelos tribunais superiores pode contemplar a pluralidade encontrada em relações homoafetivas? Dessa forma, o presente trabalho investiga como ocorre o acesso à justiça e reconhecimento de direitos de pessoas em relações homoafetivas nos tribunais superiores brasileiros, apontando a expressiva participação da advocacia privada nesses processos, além de indicar os conteúdos decisórios que se reiteram nestes Tribunais nos últimos sete anos e que indicam um panorama judicial afastado de debates presentes em outras ciências sociais e humanas no que tange questões de gênero e sexualidade, assim como de muitas pautas e abordagens defendidas pelo movimento social de lésbicas, gays, bissexuais, travestis, transexuais e intersexos (LGBTI).

Salienta-se que a sigla LGBTI utilizada para definir os indivíduos presentes no movimento social foi escolhida em virtude da comum utilização por grupos civis e pela Organização das Nações Unidas no tratamento de temas relacionados a estes sujeitos, incluindo a letra "I", referente aos intersexos que podem ser entendidos como os indivíduos que nascem com uma anatomia reprodutiva e/ou sexual não condizente com uma condição típica de sexo feminino ou masculino. No entanto, cabe destacar que as reflexões aqui exercidas acerca dos contextos vivenciados por pessoas em relações homoafetivas expandem-se para qualquer 
pessoa que se identifique com tal condição, não se restringindo à sigla LGBTI.

Levanta-se como hipótese inicial que o Judiciário deve buscar um debate interdisciplinar sobre as questões de gênero e sexualidade, por meio de uma junção entre forças sociopolíticas e estratégias estatais, no intuito de alcançar um entendimento complexo sobre as realidades vivenciadas de forma interseccionada por indivíduos em relações homoafetivas, pois assim, inicia-se um processo para o alcance de um reconhecimento plural desses sujeitos.

O texto estrutura-se inicialmente com um tópico (2) que apresenta a metodologia utilizada na coleta da amostra de decisões retiradas dos tribunais superiores, que apresenta brevemente os resultados e aponta os demais processos metodológicos utilizados na elaboração do artigo. Em seguida há o primeiro capítulo do desenvolvimento (tópico 3), que trata da participação do movimento LGBTI no reconhecimento da união homoafetiva e demais direitos ligados à configuração familiar, apresentando um panorama histórico das forças sociais empreendidas por este grupo na busca por seus direitos. Posteriormente, o segundo capítulo (tópico 4) aborda o percurso do reconhecimento de direitos homoafetivos, em específico a união estável homoafetiva e sua conversão em casamento, os direitos previdenciários e de sucessão advindos destas relações familiares e a adoção homoparental, traz ainda um debate sobre diversidade sexual, além de apontar análises sobre os dados recolhidos nos tribunais superiores. O terceiro capítulo (tópico 5) evidencia a questão da pluralidade social, econômica e cultural que constituem os indivíduos em questão, ao traçar observações acerca da efetividade do reconhecimento de direitos pelos tribunais superiores no Brasil, por meio de uma análise acerca do acesso a justiça desses sujeitos pela advocacia privada e do papel da Defensoria Pública nesse cenário. Por fim, são apresentadas as considerações finais (tópico 6).

\section{CAMINHOS METODOLÓGICOS}

A metodologia se constitui na análise qualitativa de decisões envolvendo uniões entre pessoas do mesmo sexo, utilizando como recorte institucional, os casos levados ao Supremo Tribunal Federal (STF) e ao Superior Tribunal de Justiça (STJ), nos últimos sete anos (20112018), tal escolha se deu pela relevância e possibilidade dos tribunais superiores influenciarem decisões de outras instâncias ou vincularem todos os membros do Poder Judiciário. Já o marco temporal escolhido pretendeu observar os processos afetados pelo julgamento da ADI 4.277 e ADPF 132, quando as uniões estáveis homoafetivas passam a ter maior expressividade e legitimidade no Judiciário. 
Os dados analisados foram coletados nos sítios do STF (www.stf.jus.br) e STJ (www.stj.jus.br) no período de 01 de maio de 2011 a 01 de maio de 2018, na busca na área de pesquisa jurisprudencial por termos como "união civil entre pessoas do mesmo sexo"; “casamento homoafetivo"; "união homoafetiva"; “ADI 4.277”; “ADPF 132”. Na coleta feita no STF foram encontrados: 11 Acórdãos; 68 Decisões Monocráticas. Na coleta feita no STJ foram encontrados: 13 Acórdãos; 124 Decisões Monocráticas.

Além disso, há um processo exploratório de teorização crítica por meio da metodologia de revisão bibliográfica, somada a análise das decisões, que se preocupou em observar nos conflitos judiciais as questões críticas inerentes à realidade LGBTI.

\section{DO COMBATE INSTITUCIONAL À CONQUISTA DE DIREITOS: O PERCURSO DO MOVIMENTO LGBTI NO BRASIL}

De acordo com Gohn (2011), os movimentos sociais representam ações sociais coletivas de caráter sociopolítico e cultural que promovem formas distintas de busca por efetivação de demandas, no caso do Movimento LGBTI, os indivíduos clamam por direitos humanos basilares, dignidade pública e políticas sociais que contemplem a esfera que os circundam. No Brasil, os conflitos gerados por estas demandas estão evidenciados no Judiciário e nos movimentos sociais (RIOS, 2011).

Segundo Facchinni e Simões (2009), o movimento social LGBTI brasileiro, enquanto movimento social organizado, nasceu na década de 1970 quando era chamado de Movimento Homossexual Brasileiro (MHB) e pode ser dividido em momentos também chamados pelos autores de "ondas". A primeira onda seria marcada pelo fim do regime militar no Brasil e expressaria um caráter revolucionário por suas pautas políticas e pela busca de uma igualdade entre os membros que gradativamente contribuiu para a construção de uma identidade LGBTI. A segunda onda concentra-se no período de redemocratização em fins da década de 1980, quando se acentua a participação do movimento social LGBTI no cenário público. E, por fim, a terceira onda teria vigorado na década de 1990, com o estabelecimento de relações com instituições estatais e não estatais.

A criação do grupo Somos em São Paulo e do Jornal Lampião da Esquina no Rio de Janeiro em 1978, configuram-se como os marcos iniciais da construção de um movimento político de lésbicas, gays, bissexuais, travestis, transexuais e intersexuais no país. O grupo foi criado em pleno a Ditadura Militar e apresentou a primeira proposta de politização de questões 
entendidas atualmente como pertencentes ao grupo LGBTI, com um caráter contestatório e antiautoritário, foi inspirado no movimento argentino Nuestro Mundo da Frente de Liberación Homossexual (FLH), que tinha como proposta discutir a homossexualidade por meio das vivências de seus integrantes. Já o jornal circulou entre os anos de 1978 e 1981 e resistia à Ditadura por meio de publicações voltadas à realidade e questões de indivíduos marginalizados por suas práticas e identidades sexuais (SIMÕES, FACCHINI, 2009; GREEN, 2000).

Na chamada segunda onda, o "Grupo Gay da Bahia" e o "Triângulo Rosa", foram fundamentais para a passagem do movimento LGBTI, de uma resistência à institucionalidade para uma organização política voltada para a conquista de direitos civis, combate à discriminação e violências e estabelecimento de organizações de caráter formal. Nesse período, o movimento LGBTI criava as suas bases políticas e reinvindicava suas principais demandas. O segundo momento do movimento LGBTI brasileiro, foi abalado pela associação entre AIDS (Síndrome da Imunodeficiência Adquirida) e homossexualidade, acentuada pela epidemia da doença no sistema imunológico causada pelo vírus HIV que era considerada a "peste gay", o que acarretou em uma dispersão do movimento e diminuição considerável do número de grupos e organizações pelo Brasil, devido a uma esfera discriminatória e odiosa gravemente acentuada na sociedade (FACCHINI, 2005; SIMÕES, FACCHINI, 2009).

A partir dos anos 1990 inicia-se a terceira onda do movimento LGBTI, com o expressivo crescimento de grupos e organizações e sua difusão em todo o Brasil. O novo panorama social do movimento foi possível por um conjunto de fatores como a organização de uma resposta coletiva à epidemia de HIV/AIDS, com a implementação de uma política de prevenção às doenças sexualmente transmissíveis e à AIDS, que foi estruturada conjuntamente pelo Estado e pela sociedade civil que empreenderam forças para a promoção de pautas voltadas ao incentivo de políticas de identidade como uma estratégia para a diminuição da vulnerabilidade de populações estigmatizadas (FACCHINI, 2009).

Em 1995, funda-se a ABGLT (Associação Brasileira de Lésbicas, Gays, Bissexuais, Travestis, Transexuais e Intersexos) a maior associação do gênero na América Latina e Caribe, que foi criada com o objetivo e a missão de promover ações que garantam a cidadania e os direitos humanos de pessoas LGBTI. A criação da ABGLT pode ser apontada como marco na construção de uma perspectiva do movimento LGBTI voltada para a discussão pública de direitos e garantias, objetivos que se tornaram presentes em organizações pelo Brasil e fomentaram o terreno para um movimento destinado a obter direitos e políticas públicas para a população que o compõe (SIMÕES, FACCHINI, 2009). 
No processo de consolidação de direitos e reconhecimento das pautas do movimento LGBTI no país, destaca-se a realização da Conferência Nacional GLBT em Brasília no ano de 2008, que foi precedida de reuniões regionais e estaduais que culminaram em 510 propostas e contaram com a participação de cerca de dez mil pessoas. O Brasil foi o primeiro país a promover uma atividade dessa proporção e natureza, o que demonstrou o compromisso do Estado brasileiro com a promoção dos direitos de indivíduos LGBTI (BRASIL. Presidência da República. Secretaria Especial de Direitos Humanos, 2008).

No Brasil, a relação entre sexualidade e direitos tem sido efetivada especialmente por meio da atuação dos movimentos feminista e LGBTI. As primeiras políticas públicas brasileiras cujo foco foram homossexuais visavam o combate à epidemia do HIV/Aids no início dos anos 1990. O primeiro documento oficial brasileiro a reconhecer publicamente homossexuais na esfera da promoção dos direitos humanos é o Plano Nacional de Direitos Humanos (PNDH), feito em 1996 (FACCHINI, 2005).

A partir da criação do Conselho Nacional de Combate à Discriminação (CNCD) em 2001 e com a elaboração do PNDH II em 2002, são incluídas algumas ações direcionadas a pessoas LGBTI. No ano de 2003 a articulação entre as questões LGBTI e os direitos humanos recebe novos esforços com a criação da Secretaria Especial de Direitos Humanos (SEDH), que passa a ter status de ministério e incorpora o CNCD como instância de participação e controle social e com a designação de um grupo de trabalho para elaborar um plano de combate à homofobia que deu origem ao "Brasil Sem Homofobia - Programa de Combate à Violência e à Discriminação contra GLTB e de Promoção da Cidadania Homossexual - em seu formato interministerial (DANILIAUSKAS, 2009).

No entanto, as conquistas no âmbito jurídico pelo movimento LGBTI estão alinhadas a uma crescente judicialização dos conflitos vivenciados por estes sujeitos, o que gerou decisões judiciais e administrativas expressivas, baseadas substancialmente por entendimentos principiológicos ocasionados pela estrutura hierárquica e pela lógica da Constituição Federal, que concede aos princípios a qualidade de normas estruturais e informativas de toda a ordem jurídica (CARDINALI, 2018; SARLET, 2009).

Nesse sentido podemos citar como exemplos de direitos conquistados pelo movimento LGBTI nos últimos anos: a união homoafetiva pelo julgamento conjunto da ADI 4277 e ADPF 132, a Resolução n ${ }^{\circ} 175$ do Conselho Nacional de Justiça que em 2013 impediu a recusa dos cartórios em realizarem casamentos entre pessoas do mesmo sexo e mais recentemente, o julgamento em março de 2018 da ADI 4275 pelo STF, que consolidou o entendimento do 
Supremo de ser possível a alteração do nome e do gênero no assento do registro civil, mesmo sem a realização de procedimento cirúrgico de redesignação sexual.

Portanto, o debate sobre a pluralidade social presente em Estados democráticos contemporâneos como o Brasil é de grande contribuição para o estabelecimento de mecanismos capazes de alcançarem um reconhecimento complexo e efetivo de indivíduos historicamente marginalizados por suas práticas e representações sexuais e de gênero.

\section{O DEBATE SOBRE A DIVERSIDAdE SEXUAL E A CONSOLIDAÇÃO DE DIREITOS NOS TRIBUNAIS SUPERIORES}

O Poder Judiciário possui uma atuação expressiva no processo legislativo e na elaboração de políticas públicas, constituindo um papel decisivo para a eficácia de leis e podendo restringir previamente as alternativas políticas disponíveis para o Poder Executivo e Legislativo no momento da estruturação de programas. Nesse sentido, o Judiciário pode ser como uma autoridade política (TAYLOR, 2007).

A partir da redemocratização brasileira os tribunais judiciários, por suas características institucionais próprias, conceberam-se como uma arena aberta à manifestação política de interesses individuais e coletivos. Assim, tribunais e seus juízes constroem um processo de mapeamento de demandas e aspirações sociais sobre questões coletivas, dentre elas a busca pelo reconhecimento efetivo de direitos para a população LGBTI (VILHENA, 2004).

A constante judicialização dessas questões indica a valorização da seara judicial pelos movimentos LGBTI em detrimento de outras vias, o que se relaciona com os obstáculos encontrados no legislativo para a inserção dos debates propostos por esses indivíduos. Assim, o Judiciário passa a ser um local propositivo e de inclusão das pautas LGBTI, visto que os espaços políticos majoritários estão restritos as suas demandas, tornando o judiciário a via política para o debate e reconhecimento de direitos para este grupo social (AGUIÃO, VIANNA, GUTTERRES, 2014).

As decisões estipuladas em tribunais e órgãos administrativos têm sido meios constantemente utilizados pela população LGBTI na promoção de alguns direitos e efetivação de outros já existentes. Nesse sentido, os tribunais promovem interpretações que evocam princípios constitucionais e normas de direitos humanos para determinarem a existência e a necessidade de direitos a estes indivíduos (RIOS, 2013).

Os dados coletados no Supremo Tribunal Federal e Superior Tribunal de Justiça, no 
período de 2011 a 2018 evidenciam que grande parte dos conflitos judiciais acerca de relações homoafetivas se trata de ações de reconhecimento da vida em comum através da instituição da união estável. As decisões afastam a necessidade do caráter "diversidade entre os sexos" para configurar uma união estável. Assim, os tribunais têm reconhecido a união estável de pessoas de mesmo sexo, por uma interpretação extensiva ou analógica do art. 1.723 do Código Civil, desde que sejam demonstrados: convivência pública, contínua e duradoura estabelecida com o objetivo de constituir família e ausência dos impedimentos ao casamento previstos no art. 1.521 do Código Civil de 2002.

As uniões homoafetivas têm como marco o momento em que suas ações passaram a ser julgadas pelas varas de família e pelas câmaras especializadas em Direito de Família, o que passou a acontecer nos anos 2000, pois até então as uniões entre pessoas do mesmo sexo tinham os juizados cíveis como competentes para julgá-las e eram tratadas como sociedades de fato, ou seja, as uniões homoafetivas eram lidas como acordos civis de conteúdo estritamente patrimonial. Essa migração foi uma iniciativa do Poder Judiciário do Estado do Rio Grande do Sul e se estendeu para os outros estados com base na interpretação de alguns princípios constitucionais. Ressalta-se ainda, o informativo 0366 do STJ de 2008, que admitiu a possibilidade jurídica do pedido de reconhecimento da união estável entre pessoas do mesmo sexo (RIOS, 2013).

O julgamento da Ação Declaratória de Inconstitucionalidade no 4.277 e da Ação de Descumprimento de Preceito Fundamental n ${ }^{\circ}$ 132, pelo Supremo Tribunal Federal em maio de 2011 formalizou a família homoafetiva no ordenamento jurídico brasileiro ao estender o regime jurídico da união estável às uniões homossexuais em todos os estados da federação brasileira.

As ações se fundamentaram em princípios constitucionais e defenderam que o não reconhecimento da união entre pessoas do mesmo sexo implicaria em violação dos princípios constitucionais da dignidade da pessoa humana (art. $1^{\circ}$, inciso III), da proibição de discriminações odiosas (art. $3^{\circ}$, inciso IV), da igualdade (art. $5^{\circ}$, caput), da liberdade (art. $5^{\circ}$, caput), e da proteção à segurança jurídica. O STF entende que o art. $3^{\circ}$, inciso IV veda as discriminações odiosas ao afirmar o dever de: "promover o bem de todos, sem preconceitos de origem, raça, sexo, cor, idade e quaisquer outras formas de discriminação"; o princípio da segurança jurídica foi citado pela ADI n 4.277/2011 e ADPF no 132/2011 para conferir a possibilidade dos casais homoafetivos disporem de direitos e garantias constitucionais de forma satisfatória. 
A concepção de segurança jurídica fortalecida nesses processos possibilitou a exigência de que os cartórios de registro civil registrassem a declaração de união civil entre pessoas de mesmo sexo. No entanto, mesmo com a autorização do registro da união estável ainda havia questões acerca de sua conversão em casamento. Nesse sentido, surge a Resolução $n^{\circ} 175$, de 14 de maio de 2013, aprovada durante a 169ª Sessão Plenária do Conselho Nacional de Justiça (CNJ), a qual estabeleceu que os cartórios de todo o País não poderiam mais recusarse à conversão da união civil em casamento e permitiu a celebração de casamentos civis entre pessoas do mesmo sexo (LOPES, 2014).

A partir do reconhecimento da união estável e do casamento civil homossexual, observa-se nos tribunais um relevante número de ações sobre dissolução das uniões e a consequente meação dos bens, guarda de filhos, pensão aos cônjuges entre outras questões inerentes ao fim dessas relações. Na maioria dos casos analisados, o judiciário concedeu o direito à meação dos bens adquiridos a título oneroso na constância do relacionamento, ainda que eles tenham sido registrados em nome de apenas um dos parceiros, não se exigindo a prova do esforço comum, o que demonstra um respaldo ao informativo $\mathrm{n}^{\circ} 0472$ do Superior Tribunal de Justiça que estipulou tal entendimento (COACCI, 2014).

No que tange aos processos envolvendo direitos previdenciários, as decisões referentes à pensão pós-morte seguem o determinado pela Instrução Normativa no 25 de 07/06/20006 regulada pelo Instituto Nacional de Seguridade Social (INSS), que garante o direito à concessão de benefício ao companheiro ou companheira homossexual, tal entendimento foi ratificado definitivamente pela Instrução Normativa do INSS $n^{\circ}$ 45, de 2010, em seu art. 25, que determinou que por força da decisão judicial proferida na Ação Civil Pública $\mathrm{n}^{\circ}$ 2000.71.00.009347-0, companheiros ou companheiras homossexuais inscritos no Registro Geral da Previdência Social integram o rol dos dependentes, restando apenas comprovar a vida em comum, assim como concorrem para fins de pensão por morte e de auxílio-reclusão, com os dependentes preferenciais elencados no inciso I, do artigo 16, da Lei $\mathrm{n}^{\circ}$ 8.213/1991, para óbito ou reclusão ocorridos a partir de 05 de abril de 1991, conforme o disposto no art. 145 do mesmo diploma legal (INSS, 2010).

Ainda na seara previdenciária, percebe-se uma interpretação dos tribunais superiores correlata com a Lei $\mathrm{n}^{\circ} 12.873$, de 24 de Outubro de 2013, que concede direitos de licença maternidade equiparados entre homens e mulheres e que ratificou um entendimento jurisprudencial que já existia acerca do benefício de licença maternidade/paternidade, o qual teve sua interpretação estendida por analogia aos pais solteiros e pais homossexuais a partir da 
Lei 12.010/2009, que dispõe sobre a adoção e que conferiu direito à licença para adotantes. Assim, tal direito foi estendido e consolidado na jurisprudência para homens solteiros e homens homossexuais, baseando-se nas evoluções dos conceitos de família, ao incluir os arranjos familiares monoparentais e homoparentais e ao priorizar os princípios da dignidade humana e de proteção à infância.

A adoção em famílias homoparentais também aparece nas decisões analisadas, principalmente em questões sobre o registro dos filhos adotados por casais homossexuais. A adoção pode ser conceituada como uma modalidade de filiação constituída por meio do amor e das relações puramente afetivas entre pais e filhos, gerando vínculo de parentesco por opção, sem que haja necessidade da conexão biológica (DIAS, 2000).

No Supremo Tribunal Federal, destaca-se o julgamento do Recurso Extraordinário 846102/ PR interposto pelo Ministério Público do Paraná contra decisão do Tribunal de Justiça do Paraná que concedeu o direito de adoção por um casal homoafetivo formado por dois homens. O MP alegou que eles não constituíam uma família, mas o STF acabou por reconhecer pela primeira vez o direito de adoção por casal homossexual com o julgamento ocorrido em 05 de março de 2015.

A ministra relatora Carmen Lúcia acentuou que as uniões homoafetivas já são reconhecidas como entidades familiares e determinou que não existe motivos para criar obstáculos onde a lei não prevê, afastando os argumentos do Ministério Público que pleiteou uma adoção restrita a um indivíduo de sexo oposto e maior de 12 (doze) anos de idade. Assim, a ministra expressou que restringir a adoção por um casal homoafetivo pela delimitação de sexo e idade do adotado seria transformar a sublime relação de filiação por adoção em ato de caridade provido de obrigações sociais e totalmente desprovido de amor e comprometimento.

A partir dos primeiros casos de reconhecimento de adoção por casais homossexuais nos tribunais ocorreu a abertura para que outras famílias pleiteassem este direito. Dentre as ações analisadas chama a atenção o HC nº 404545/ CE (STJ), Relator: Ministro Ricardo Vilas Bôas Cueva, julgado em 22/08/2017 pela Terceira Turma (T3), referente à guarda e adoção de menor impúbere com 10 meses de vida por um casal homossexual, em um caso em que a mãe abandonou espontaneamente a criança com 17 (dezessete) dias de vida na porta da casa do casal e este recebeu a criança como filho e estabeleceu convívio e relação familiar com o menor. A decisão aponta que a criança vem recebendo todos os cuidados necessários para seu bem-estar físico e psíquico e salienta o interesse concreto do casal em adotá-la, com o procedimento iniciado e destaca que uma decisão de acolhimento institucional do menor nutriria aspectos 
teratológicos, ou seja, completamente contrários a um sentido moral, de boa-fé, configurandose como uma determinação ilógica e fora do bom senso. Assim, julgou-se que a observância do cadastro de adotantes não é absoluta e em virtude do melhor interesse da criança foi concedida a ordem de permanência do menor com o casal homoafetivo de forma unânime pelo tribunal.

Nesse sentido, a Terceira Turma expressou que vem se atribuindo valor jurídico ao afeto e que a dimensão socioafetiva da família ganha espaço na doutrina e jurisprudência em detrimento das relações de consanguinidade. O tribunal não levantou qualquer questão acerca da adoção por um casal homossexual e demonstrou a consolidação de uma interpretação congruente com uma concepção de família baseada na afetividade, sem restrições à orientação sexual dos pais.

Ao observamos as decisões sobre os direitos às famílias homoafetivas e ao destacarmos o processo de inserção das mudanças legislativas e jurisprudenciais acerca dos direitos de família nos tribunais superiores brasileiros, percebemos a importância de um debate que inclua às questões inerentes a diversidade sexual para o enfrentamento de ações que deslegitimam essas conquistas, assim como para ampliá-las e torná-las efetivas de forma plural.

De acordo com Louro (2008), o reconhecimento do instituto do casamento civil para pessoas de mesmo sexo enfrenta recepções sociais negativas, especialmente pelo extrato sociocultural brasileiro permeado por normatividades como o casamento católico-romano heterossexual, a necessidade de procriação, dentre outros constructos sociais que são perpetuados como princípios morais, os quais desembocam em práticas e comportamentos de negação à diversidade sexual e opressão das identidades e práticas vistas como destoantes de um padrão heteronormativo.

No entanto, é dever do Estado afastar ações discriminatórias contra minorias de suas políticas e do Judiciário, devido ao princípio político da laicidade. Porém, mesmo diante dos progressos legislativos acerca das uniões homoafetivas, ainda persiste uma concepção sexual acerca das relações familiares que resguarda a associação entre sexualidade, conjugalidade, reprodução, com enfoque na idealização de um casal exclusivo e o mais homogâmico possível em termos raciais, classistas, religiosos, educacionais, etc. Além das normas de gênero que impõem representações masculinas para homens e femininas para mulheres (MELLO, et al. 2012).

Dessa forma, torna-se essencial um entendimento acerca das construções sociais de gênero e sexualidades, assim como dos mecanismos de reprodução de uma heteronormatividade binária que determinam arcabouços de invisibilidade social sobre 
identidades e práticas desviantes das expectativas construídas sobre os corpos. Pois assim, torna-se perceptível que a sexualidade é uma realidade socialmente construída como apontam Foucault (2004), Weeks (2001) e Rubin (1989).

Todavia, a análise feita sobre os 24 acórdãos e 192 decisões monocráticas nos tribunais superiores brasileiros indica uma totalidade de decisões afastadas de argumentações voltadas para um campo interdisciplinar entre o direito e demais ciências sociais e humanas. Os argumentos jurídicos são voltados exaustivamente para princípios como a igualdade e liberdade, assim como para o uso expressivo de menções ao conteúdo do julgamento da ADI 4.277 e da ADPF 132, o que demonstra a reiteração de uma estrutura argumentativa comum entre os casos envolvendo relações homoafetivas que reproduz incoerências com o uso de expressões como "homossexualismo", "transexualismo", “opção sexual”, termos que indicam patologias e entendimentos inadequados sobre a diversidade sexual.

Sendo assim, está evidenciado um desafio para a doutrina e jurisprudência no sentido de buscarem nos estudos de gênero e sexualidade um entendimento para além das garantias formais de direitos civis e previdenciários para uniões homoafetivas, a partir de um debate sobre pluralidade e reconhecimento efetivo para indivíduos em relações afetivas de conjugalidade e/ou filiação não heteronormativas.

\section{O RECONHECIMENTO DA PLURALIDADE}

Em As fontes do Self, Charles Taylor (2009) questiona uma compreensão monológica da identidade e do reconhecimento modernos gerados em torno do individualismo e do utilitarismo. Segundo o autor, o individualismo moderno estipulou uma pessoa autocentrada em um processo de isolamento dos outros indivíduos. Em contrapartida, o autor concebe que existe um inevitável vínculo entre as identidades destoantes e que a expressão e constituição desses indivíduos se dão por mecanismos interlocutórios com os outros seres humanos e comunidades, sendo necessário um processo de recuperação da dignidade e igualdade por essa interlocução para que não se estabeleça um panorama problemático acerca dos modos de ser e de perceber os sujeitos.

No entanto, as interações sociais e a produção e reprodução das construções efetivadas no meio social possibilitam espaços de visibilidade e representações distintas entre as pessoas, processo que desemboca na marginalização de sujeitos destoantes da norma de visibilidade social. Nesse sentido, a precariedade vivenciada por indivíduos nas estruturas sociais está 
estritamente ligada às normas de gênero, uma vez que aqueles que não cumprem as expectativas heteronormativas e não vivem seu gênero de formas inteligíveis estão expostos a um risco mais elevado de assédio, patologização e violência (BUTLER, 2018).

Dessa forma, há um questionamento sobre a proteção legal desses indivíduos, pois existe uma tendência institucional de privação de direitos civis e estigmatização para sujeitos não heteronormativos, o que ocasiona em barreiras para assistência à saúde, perante a lei e invisibilidade de relações íntimas e de parentesco. Sendo assim, torna-se importante a questão do reconhecimento pela presunção de que todos os sujeitos humanos são igualmente reconhecíveis. Contudo, e acordo com Judith Butler (2018), a normatividade de gênero cria uma condição de aparecimento no meio social, o que restringe o campo do reconhecível.

Segundo Nancy Fraser (2007), o reconhecimento é uma questão de justiça. Na luta de grupos através de movimentos sociais como o LGBTI, o "reconhecimento da diferença" emergiu como o principal conflito contra a dominação cultural do século. Nesse contexto, distinguem-se duas formas de compreensão da injustiça: a primeira seria a injustiça econômica, estabelecida na estrutura política e econômica da sociedade; e a segunda, a injustiça cultural ou simbólica, contida nos padrões sociais de representação, interpretação e comunicação (FRASER, 2006).

Diante da complexidade que tal reconhecimento envolve, as reflexões sobre as demandas pelo reconhecimento da diferença ocorrem por meio do caso a caso e acaba por considerar identidades específicas e as particularidades dos indivíduos. Assim, torna-se essencial a construção de um paradigma de justiça que recupere padrões institucionalizados de reconhecimento e de valoração cultural, com o objetivo de assegurar a real igualdade de oportunidade de estima social. Trata-se da "condição intersubjetiva" de paridade participativa, no intuito de excluir normas institucionalizadas que sistematicamente depreciam algumas categorias de pessoas e as características associadas a elas (FRASER, 2007).

Nos casos de grupos historicamente oprimidos, como os LGBTI, direitos diferenciados de proteção e de benefício são estratégias necessárias e podem ser legitimados no intento de equilibrar desigualdades. Assim, estes direitos diferenciados se justificariam em um novo sentido de justiça correlacionado com uma política verdadeiramente democrática, orientada para uma dissolução das desigualdades historicamente institucionalizadas que determinam a opressão distributiva (YOUNG, 2000).

A constituição de uma política democrática que insira pessoas LGBTI por meio de manifestações, esforços legislativos ou demandas por políticas públicas precisam fazer 
reivindicações em nome desses sujeitos, mas este processo não pode ocorrer sem uma atitude crítica, que desnaturalize a ideia de sujeito político, como descritivo de uma essência previamente dada, pois deve reconhecer o caráter contingente de sua construção, salientando as exclusões que perpassam a constituição desses sujeitos (BUTLER, 1998, 2002).

Os agrupamentos sociais, movimentos políticos, assim como as relações familiares compostos por lésbicas, gays, bissexuais, travestis, transexuais e intersexos compõem um conjunto complexo de sujeitos políticos que procuram lidar com essa pluralidade e se afirmar como sujeitos de direitos e integrantes dessa comunidade mais ampla composta pelos cidadãos brasileiros. Nenhuma dessas duas comunidades pode atualmente ser imaginada como algo homogêneo e é com esse fato que tanto o Estado quanto o movimento LGBTI procuram lidar (ANDERSON, 1991).

Dentre os diversos aspectos da pluralidade brasileira que podemos visualizar efeitos na realidade LGBTI, há um contraponto no acesso aos tribunais, relacionado aos fatores socioeconômicos que incidem sobre os sujeitos em questão. Isso porque, destaca-se como resultado retirado da amostra de onze (11) acórdãos analisados do STF e treze (13) do STJ, que em ambos os tribunais não existem acórdãos oriundos de processos em que as partes tenham sido patrocinadas pela Defensoria Pública. Em relação às decisões monocráticas, o Supremo Tribunal Federal tem oito (8) processos em que os sujeitos LGBTI foram representados pela Defensoria Pública, de um total de sessenta e oito (68) decisões monocráticas analisadas. Ao passarmos a análise para os dados coletados no Superior Tribunal de Justiça, identificamos onze (11) decisões monocráticas nas quais os direitos foram tutelados pela Defensoria Pública, em um total de cento e vinte e quatro (124) decisões. Tais resultados demonstram que a advocacia privada assume papel majoritário nos tribunais superiores brasileiros em casos envolvendo direitos previdenciários, casamento, união estável e demais direitos oriundos de uniões homossexuais.

Nesse sentido, adentra-se no aspecto da Defensoria Pública Brasileira como agente transformador da realidade social e ao qual incumbe a defesa de direitos às minorias marginalizadas, visto que, a Defensoria Pública no Brasil foi criada, dentre outras finalidades, para a implementação de políticas inclusivas como estipula a Constituição Federal em seu art. $5^{\circ}$ que assegura a igualdade entre todos perante a lei, sem distinção de qualquer natureza, garantindo-se direitos como a liberdade e igualdade. O inciso LXXIV do mesmo artigo afirma que o Estado prestará assistência jurídica integral e gratuita aos que comprovarem insuficiência de recursos. 
No que tange a definição de indivíduos hipossuficientes, entende-se sem recursos financeiros, bem como abrange a insuficiência organizacional para implementação dos direitos de categorias que do ponto de vista estrutural são hipossuficientes. Pode-se afirmar então, que a Defensoria Pública também é um meio pelo qual o indivíduo conhece e reconhece seus direitos e suas obrigações e que abrange a assistência e consultoria para nutrir os aspectos democráticos no meio jurídico, como prevê a Carta Magna.

Dessa forma, a Defensoria Pública tem como missão a orientação jurídica, a promoção dos direitos fundamentais e a defesa dos direitos individuais e coletivos, de forma integral e gratuita aos necessitados. Assim, a Defensoria Pública deve expandir seu papel no sentido de cumpri-lo da forma mais ampla possível no processo de reconhecimento de direitos e garantias para pessoas LGBTI.

A ideia de reconhecimento ocorre pela declaração de existência desses direitos. Todavia, a efetivação dos mesmos depende de um contexto mais complexo, pois uma simples concepção de sociedade de iguais é insatisfatória, sendo necessária uma igualdade complexa, que alcance o pluralismo social e que nos leve a estratégias diferenciadas, locais e subjetivas para a solução de problemas oriundos da diversidade cultural (WALZER, 2003).

A introdução de um debate acerca da interseccionalidade ganha espaço nas questões de pluralidade social. A interseccionalidade refere-se a uma teoria transdisciplinar, cujo objetivo é entender a complexidade das identidades e das desigualdades sociais por intermédio de um enfoque integrado. Nesse sentido, a interseccionalidade refuta o enclausuramento e a hierarquização dos grandes eixos da diferenciação social que são as categorias de sexo/gênero, classe, raça, etnicidade, idade, deficiência e orientação sexual. O enfoque interseccional ultrapassa o limite do simples reconhecimento das múltiplas opressões que operam por meio dessas categorias, pois visualiza uma interação entre essas categorias na produção e na reprodução das desigualdades sociais (BILGE, 2009; HIRATA, 2014).

O debate sobre interseccionalidades é relevante no estudo da multiplicidade de fatores que categorizam os corpos e os dimensionam, pois permite perceber a coexistência de diversas abordagens (PISCITELLI, 2008). Segundo Kimberlé Crenshaw (2002), a noção de intersecção de variadas subordinações leva à superação da ideia de superposição de opressões, visto que a interseccionalidade remete aos contornos sociais e políticos que geram as confluências entre os eixos de subordinação e ocasionam o desempoderamento sistemático dos sujeitos.

De acordo com Prado e Machado (2008), o papel da sociedade na manutenção ou rompimento da subalternidade nas relações de poder é fundamental, visto que o reconhecimento 
das minorias sociais requer a visibilidade dos antagonismos. Portanto, a opressão do grupo LGBTI é uma lógica de hierarquização oriunda de discursos hegemônicos que conduzem os sujeitos não heterossexuais a se posicionarem de forma subalterna, seja pela lógica da excentricidade e/ou pelo preconceito, o que alinhado a demais contextos opressivos vivenciados na pluralidade social, os impõe a ultrapassagem de barreiras interseccionadas que atuam de forma conjunta no processo de exclusão destes indivíduos.

\section{CONSIDERAÇÕES FINAIS}

A população LGBTI busca pela efetivação de direitos no âmbito do Poder Judiciário e no plano normativo com o objetivo de combate às discriminações oriundas de um extrato sociocultural heteronormativo, que implicam em conflitos que se evidenciam no Judiciário. Dessa forma, as demandas oriundas das relações homoafetivas ganharam destaque nas decisões dos tribunais superiores brasileiros. No entanto, a amostra de decisões coletadas demonstra a ausência de uma abordagem ampla das questões de gênero e sexualidade, o que dificulta um processo de igualdade complexa, pois não se leva em conta os processos interseccionais de exclusão social vivenciados por esses indivíduos.

Além disso, não há uma problematização acerca de fatores como os obstáculos de acesso à justiça para indivíduos hipossuficientes, com baixa educação formal e/ou de extratos socioculturais marcados por uma expressiva realidade lgbtifóbica. Assim, o problema da desigualdade no acesso à justiça nos imputa o desafio de um reconhecimento plural, democrático e efetivo dos direitos da população LGBTI.

$\mathrm{O}$ reconhecimento auferido pelo STF e STJ aos direitos relacionados às uniões homossexuais e suas conjunturas familiares carece de um olhar crítico, no intuito de verificar a real efetividade concedida por meio do Judiciário às questões LGBTI. Assim, torna-se crucial a busca pela igualdade complexa, que alcance o pluralismo social e que nos leve a estratégias diferenciadas, locais e subjetivas como a redistribuição de renda, o controle democrático do investimento, o reconhecimento e a valorização da diversidade cultural e a extensão do papel da Defensoria Pública para a solução de problemas oriundos da pluralidade.

Diante das análises, estudos e reflexões feitos a partir da amostra de decisões coletadas nos tribunais superiores, compreende-se que um reconhecimento complexo e plural da diversidade LGBTI pelo Judiciário necessita inicialmente das contribuições construídas em estudos de gênero e sexualidade para que haja uma real compreensão das questões que estão 
embutidas em suas realidades, não só de forma objetiva e em termos de proteção legal, mas acerca das posições sociais desses indivíduos, assim como das violências vivenciadas pelo grupo e de suas múltiplas características, que acabam lhes conferindo formas de opressão interseccionadas, seja por questões étnicas, raciais, culturais, socioeconômicas ou até mesmo por suas particularidades e subjetividades.

Assim, uma via para o reconhecimento da pluralidade das relações, organizações, práticas e identidades não-heterossexuais está na construção conjunta das forças sociais empreendidas pelos movimentos político-sociais arquitetados pela população LGBTI e da atuação de um Estado comprometido em afastar conjunturas socioculturais opressivas e discriminatórias de suas políticas, agentes e instituições, ou seja, que vise uma espécie de emancipação estatal por vias verdadeiramente democráticas, que o livre das estruturas normativas atuantes sobre os sujeitos e suas realidades e identidades multifacetárias e interseccionais.

\section{REFERÊNCIAS BIBLIOGRÁFICAS}

AGUIÃO, Silvia; VIANNA, Adriana; GUTERRES, Anelise. Limites, espaços e estratégias de participação do movimento LGBT nas políticas governamentais. In: LOPES, José Sérgio Leite; HEREDIA, Beatriz (orgs.). Movimentos sociais e Esfera pública: o mundo da participação. Rio de Janeiro, CBAE, 2014, pp. 238-269.

ANDERSON, Benedict. Imagined communities: reflections on the origin and spread of nationalism. Londres: Verso, 1991[1983].

BILGE, Sirma. Théorisations féministes de l'intersectionnalit. Diogène, 1 (225): 70-88. Montreal, 2009.

BUTLER, Judith. Fundamentos contingentes: o feminismo e a questão do pós-modernismo. Cadernos Pagu, Campinas, n. 11, p. 11-42, 1998.

Cuerpos que importan: sobre los límites materiales y discursivos del "sexo". Buenos Aires: Paidos, 2002.

. Corpos em Aliança e a Política das Ruas: Notas para uma teoria performativa de

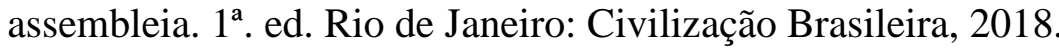

BRASIL. Constituição Federal de 1988. Disponível em: < http :// www .planalto.gov .br/ ccivil_03/constituicao/constituicao.htm>. Acesso em 13 de junho de 2018.

.Instituto Nacional do Seguro Social. Instrução Normativa n²5, de 07 de Junho de 2000. Diário Oficial [da] União. 08 de Junho de 2000. Disponível em: http://sislex.previdencia.gov.br/paginas/38/INSS-DC/2000/25.htm. Acesso em: 11. Dez.2017. 
. Instituto Nacional do Seguro Social. Instrução Normativa N45, de 06 de Agosto de 2010. Diário Oficial [da] União. 11 de Agosto de 2010. Disponível em: http://sislex.previdencia.gov.br/paginas/38/INSS-PRES/2010/45_1.htm\#cp1_s2. Acesso em: 11 de Junho de 2018.

. Lei $n^{\circ} 6.015$ de 31 de Dezembro de 1973. Dispõe sobre os registros públicos, e dá outras providências. Diário Oficial [da] União. Disponível em: http://www.planalto.gov.br/ccivil_03/leis/L6015consolidado.htm. Acesso em: 10 de junho de 2018.

.Lei 8.213 de 24 de Julho de 1991. Dispõe sobre os Planos de Benefícios da Previdência Social e dá outras providências. Diária Oficial [da] União. Disponível em: <www.planalto.gov.br/ccivil_03/leis/18213cons.htm>. Acesso em: 10 de junho de 2018.

.Lei 10.406 de 10 de Janeiro de 2002. Institui o Código Civil. Diário Oficial [da] União. Disponível em: <http://www.planalto.gov.br/ccivil_03/leis/2002/L10406.htm>. Acesso em: 10 de julho de 2018.

.Lei 12.010 de 03 de Agosto de 2009. Dispõe sobre a adoção. Diário Oficial [da] União. 04 de Dezembro de 2009. Disponível em: http://www.planalto.gov.br/ccivil_03/_ato2007-2010/2009/lei/112010.htm. Acesso em: 11 de junho de 2018.

. Lei $n^{\circ} 12.873$ de 24 de Outubro de 2013. Altera as Leis nos 8.212, de 24 de julho de 1991, e 8.213, de 24 de julho de 1991, [...]. Diário Oficial [da] União. Disponívelem:<http://www.planalto.gov.br/ccivil_03/_ato2011-2014/2013/lei/112873.htm>. Acesso em: 10 de Julho de 2018.

Presidência da República. Secretaria Especial de Direitos Humanos. Anais da Conferência Nacional de Gays, Lésbicas, Bissexuais, Travestis e Transexuais - GLBT. Direitos Humanos e políticas púbicas: o caminho para garantir a cidadania de GLBT. Brasília: SEDHPresidência da República, 2008.

Supremo Tribunal Federal. Ação Direta de Inconstitucionalidade 4.277 e Arguição de Descumprimento de Preceito Fundamental 132 Disponível em: <http://redir.stf.jus.br/paginadorpub/paginador.jsp?docTP=AC\&docID=628633> Acesso em: 06 de julho de 2018.

Supremo Tribunal Federal. Ação Direta de Inconstitucionalidade 4.275 Disponívelem: $<$ http://www.stf.jus.br/portal/geral/verPdfPaginado.asp?id=400211\&tipo=TP\& descricao=ADI\%2F4275> Acesso em: 06 de julho de 2018.

. Supremo Tribunal Federal. Recurso Extraordinário nº 846102/PR. Relator Min. CarmenLúcia. Disponível em: <https://stf.jusbrasil.com.br/jurisprudencia/178770481/recursoextraordinario-re-846102-pr-parana>. Julgado em: 05 de março de 2015. Acesso em: 18 de Julho de 2018.

. Superior Tribunal de Justiça. Habeas Corpus no 404545/ CE. Relator Min. Ricardo $\begin{array}{ccccc}\text { Villas Boas } & \text { Cuêvar } & \text { Disponível }\end{array}$ 
https://stj.jusbrasil.com.br/jurisprudencia/473957076/habeas-corpus-hc-404545-ce-20170146674-8>. Julgado em: 22 de Agosto de 2017. Acesso em: 18 de Julho de 2018

. Superior Tribunal de Justiça. Informativo de Jurisprudência $n^{\circ} 0366$. Disponível em:<http://jurisprudenciabrasil.blogspot.com/2008/12/informativo-stj-366-superior-tribunal. html >. Acesso em: 12 de Julho de 2018

CARDINALI, Daniel Carvalho. A judicialização dos Direitos LGBT no STF: limites, possibilidades e consequências. Belo Horizonte: Arraes Editores, 2018.

COACCI, Thiago. Do homossexualismo à Homoafetividade: discursos judiciais sobre a homossexualidade no STJ e STF de 1989 a 2012. (Dissertação de Mestrado). Programa de PósGraduação em Ciência Política. Universidade Federal de Minas Gerais, Belo Horizonte, 2014.

CRENSHAW, Kimberlé. Documento para o encontro de especialistas em aspectos da discriminação racial relativos ao gênero, Estudos feministas 1, p.171-189, 2002.

DANILIAUSKAS, Marcelo. Considerações preliminares sobre as concepções e conceitos norteadores das políticas públicas de educação para a igualdade de gênero e diversidade sexual. In: Seminário Corpo, Gênero, Sexualidade. FURG, Rio Grande, 2009.

DIAS, Maria Berenice. A União Homossexual: Preconceito e Justiça. Porto Alegre: Advogado Editora, 2000.

FOUCAULT, Michel. Ética, Sexualidade, Política. Rio de janeiro, Forense Universitária, 2004

DIAS, Maria Berenice. A União Homossexual: Preconceito e Justiça. Porto Alegre: Advogado Editora, 2000.

FACCHINI, Regina. Sopa de letrinhas? Movimento homossexual e produção de identidades coletivas nos anos 90. Rio de Janeiro: Garamond, 2005.

Entrecruzando diferenças: mulheres e (homo)sexualidades na cidade de São Paulo. In: BENÍTEZ, María Elvira Díaz; FIGARI, Carlos Eduardo (Ed.). Prazeres dissidentes. Rio de Janeiro: CEPESC; Garamond, 2009.

FRASER, Nancy. Da Redistribuição ao reconhecimento? Dilemas da Justiça numa era "Póssocialista". Cadernos de Campo, 14(15),13-82, São Paulo, 2006.

Reconhecimento Sem Ética. Lua Nova, 70(1),101-138, São Paulo, 2007.

GOHN, Maria da Glória. Movimentos sociais na contemporaneidade. Revista Brasileira de Educação, 16(47),333-361, São Paulo, 2011

GREEN, James Naylor. Além do carnaval: a homossexualidade no Brasil do século XX. São Paulo: Unesp, 2000.

HIRATA, Helena. Gênero, classe e raça: interseccionalidade e consubstancialidade das relações sociais. Tempo Social: revista de sociologia da USP, 26(1), 61-73, São Paulo, 2014. 
LOPES, José Reinaldo de Lima. Da dissidência á diferença: direitos dos homossexuais no Brasil da Ditadura á Democracia. In: GREEN, James Naylor; QUINALHA, Renan (orgs.). In: Ditadura e Homossexualidades: repressão, resistência e a busca da verdade. São Carlos: EdUFScar, 2014, pp. 273-299.

LOURO, Guacira Lopes. Um Corpo Estranho: ensaios sobre sexualidade e teoria queer. Belo Horizonte: Autêntica, 2008.

MELLO, Luiz; et al. Políticas Públicas para a População LGBT no Brasil: notas sobre alcances e possibilidades. Cadernos Pagu (39), 403-429, Campinas, 2012.

PISCITELLI, Adriana. Interseccionalidades, categorias de articulação e experiências de migrantes brasileiras. Sociedade E Cultura 11 (2). pp. 263-274, 2008.

PRADO, M. A. M.; MACHADO, F. V. Preconceito contra homossexualidades: a hierarquia da invisibilidade. São Paulo: Cortez, 2008.

RIOS, Roger Raupp. As Uniões Homossexuais e a "Família Homoafetiva": o direito de família como instrumento de adaptação e conservadorismo ou a possibilidade se sua transformação e inovação. Civilistica.com. Rio de Janeiro, a. 2, n. 2, abr.-jun./2013. Disponível em: $<$ http://civilistica.com/as-unioes-homossexuais-e-a-familia-homoafetiva/>. Acesso em: $02 \mathrm{de}$ julho de 2018.

. Direitos sexuais, uniões homoafetivas e a decisão do Supremo Tribunal Federal (ADPF 132-RJ e ADI 4.277). In: RIOS, Roger Raupp; GOLIN, Célio; LEIVAS, Paulo Gilberto Cogo. Homossexualidade e Direitos sexuais: reflexões a partir da decisão do STF. Porto Alegre: Sulina, 2011, pp. 69-113.

RUBIN, Gayle. Reflexionando sobre el sexo: notas para uma teoria radical de la sexualidade. In: VANCE, Carole. (org.) Placer y peligro: explorando la sexualidade feminina. Madri, Revolución Madri, 1989, pp. 113-190.

SARLET, Ingo Wolfgang. A dignidade da Pessoa Humana e Direitos Fundamentais. $7^{\mathrm{a}}$ Ed. Porto Alegre: Livraria do Advogado, 2009.

SIMÕES, Júlio; FACCHINI, Regina. Na trilha do arco-íris: do movimento homossexual ao LGBT. São Paulo: Editora Fundação Perseu Abramo, 2009.

TAYLOR, Charles. La Politica del Reconocimiento. Em Charles Taylor. El multiculturalismo e "La Politica Del Reconocimiento" (2a ed.). México D.F: FCE, 2009.

TAYLOR, Matthew M. O Judiciário e as políticas públicas no Brasil. Dados\&, vol.\& 50, n. 2, Rio de Janeiro, 2007.

VILHENA, Óscar Vieira. Supremocracia, Revista Direito GV,8(2), p.441-464, São Paulo, 2004.

YOUNG, Iris Marion. La justicia y la Política de la diferencia. Madrid: Cátedra, 2000. 
WALZER, Michael. Esferas da justiça: uma defesa do pluralismo e da igualdade. São Paulo: Martins Fontes, 2003.

WEEKS, Jeffrey. O Corpo e a Sexualidade. In: LOURO, Guacira Lopes. (org). O Corpo Educado: pedagogias da sexualidade. Belo Horizonte, Autêntica, Belo Horizonte, pp 35-82. 